\title{
Policy response to poverty and inequality in the developing world
}

\section{Albert Berry}

Professor of Economics,

Centre for International Studies,

University of Toronto,

Canada

Berry2@chass.utoronto.ca
The author argues that the effectiveness of poverty alleviation

instruments largely depends on how poverty is defined. The aim of reducing absolute poverty chiefly entails a discussion of growth, historically the main factor in this process. If poverty is defined in relative terms, on the other hand, then it is changes in inequality that are the main factor behind variations in its incidence. In any event, the relationship between the two potential sources of poverty reduction is crucial.

This article summarizes the growth and distribution implications of growth-oriented policies in the first instance, then of distributional policies. It concludes by considering which instruments offer the best hope of reducing absolute poverty or relative poverty, and how sensitive the optimum policy combination might be to the way poverty is defined. 


\section{Introduction}

By the most common yardsticks of economic progress (per capita income or purchasing power, satisfaction of basic needs), there has been a striking decline in the incidence of poverty in the Third World, and hence in the world as a whole, over the past half century for which fairly adequate data are available. With a constant poverty line of 2001970 United States dollars, ${ }^{1}$ world poverty incidence fell from nearly half in 1950 to about a quarter in 1977 and has carried on falling since, probably to between $10 \%$ and $13 \%$ in 1995 , with the absolute number of poor declining by over $40 \%{ }^{2} \mathrm{~A}$ considerable share of this advance has reflected rapid growth and a low level of inequality in China. When that country is excluded, incidence falls more slowly, from $36 \%$ in 1950 to $24 \%$ in 1977 and somewhere between $11 \%$ and $15 \%$ by 1995 , while the absolute number of people in poverty falls modestly by perhaps $5 \%$ to $15 \%$ over the whole period, with all or nearly all of this reduction occurring since 1980. Defined by the higher poverty line of 1,000 1987 international dollars, the absolute level of poverty outside China showed a net increase during the period 1950-1995, with this pattern emerging over the recent period 1980-1995 as well as before.

The decline in poverty incidence (defined by income level) in the non-socialist world has been fitful, uneven regionally, and threatened by changes of policy and context. Accordingly, there is a good deal of concern to find a secure recipe for the sort of "growth with equity" that would bring rapid and widespread poverty alleviation. Though there is considerable agreement, at least among economists, with respect to some of the elements of a good strategy to reduce it, other possible elements are more controversial, and there is nothing approaching consensus on the relative importance of the suggested components. This paper puts forward some views on what works, and

I thank Gerry Helleiner and José Antonio Ocampo for their valuable comments on an earlier draft. Any remaining errors are my own.

${ }^{1}$ And with other country values converted to United States dollars at the purchasing power parity conversion rate.

2 Based on Berry, Bourguignon and Morrisson (1983) and Berry and Serieux (2002). emphasizes the need to base policy on a more serious analysis of human welfare than has been the case and to tighten the links between the definition of poverty and the policy response.

Any discussion of the alleviation of absolute poverty (when defined as purchasing power below some given absolute level) is necessarily also a discussion of growth. One may think of the rate of poverty alleviation as being determined jointly by the rate of average income growth and changes in the distribution of income. If distribution improves, this contributes to poverty alleviation, so growth "accounts for" less than the whole of the improvement; otherwise it "accounts for" all or more than all of the alleviation which occurs. In this mechanistic sense, the great bulk of the poverty alleviation which has occurred over the past half century, perhaps all of it, is due to growth. Over the last decade or so, increases in inequality have become the norm in developing (as well as developed) countries; growth itself is, accordingly, a less secure route to absolute poverty alleviation than before, even though it has become the sole source thereof.

It is useful to distinguish between the primary distribution of income -that which emerges from the functioning of the economy before any subsequent redistribution through taxes and transfers- and the secondary distribution which includes the effects of these. Taking this distinction into account, one may think of the challenge of poverty alleviation as involving i) growth, ii) the impacts of the particular growth pattern followed on primary distribution (sometimes positive and sometimes negative), and iii) direct poverty redressal, whereby some form of redistribution takes place to alleviate part of the poverty implicit in the primary distribution of income; this may be through the State or through private channels, such as the extended family or the community.

If relative income or consumption is a key element of the basic definition of poverty -and authors like Easterlin (1974), Scitovsky (1976) and Hirsch (1976) have argued that relative consumption is the central determinant of well-being in industrial countries- then changes in distribution are likely to be the main source of changes in poverty incidence, where poverty is defined as a low level of self-defined well-being (see 
below). In either case, it is evident that the relationship between the two potential sources of poverty reduction, namely growth and improved equity, is important. Many early post-war development theorists emphasized that growth might well worsen income distribution over a period (Kuznets, 1955). Others, including some who did not expect the early-stage worsening of distribution and some who believed that it would not be sharp enough to prevent benefits reaching the poorer groups, believed in the "trickle-down" theory, which predicts that even if growth is not designed particularly for the benefit of the poor, some of its fruits will nonetheless accrue to them. The record of the last half century has basically confirmed the trickle-down theory, at least in the sense that much poverty alleviation has been achieved, even in countries which did not seem to concern themselves much with poverty alleviation. The experience of Taiwan shows just how complementary a very equitable distribution of income can be with very fast growth, even during the early phases (Ranis, 1978). Other countries, while making the point in a less spectacular way, have records which are consistent with it. The growth/distribution discussion has thus gradually moved to a fairly general acceptance that the two objectives are not likely to be in conflict in any systematic way unless a bad combination of policies has been chosen. The range of experiences on both the growth and the distribution fronts suggests that policy may matter a great deal, i.e., that not all of the variance of outcomes is due to differing exogenous circumstances. ${ }^{3}$

Since, especially over the longer run, growth is the main factor in alleviating absolute poverty as measured in income terms, it follows that those policies adopted principally for their expected growth benefits may also be the main determinants of how poverty changes over time, with policies adopted for their expected distributional benefits playing a lesser role. In practice, some of these latter policies may in fact worsen distribution, either because governments mainly controlled by the relatively well-off shy away from implementing policies in a way which will be progressive, and/or because there remains a good deal of guesswork as to the distributional impacts of many policies.

Section II of the paper reviews the implications for both growth and distribution of those policies usually pursued with the former objective in mind, section III does the same for those policies normally pursued with distributional objectives in mind, section IV points to how sensitive the composition of the optimal policy package may be to the way poverty is defined, and section $\mathrm{V}$ presents some general conclusions on "best policies".

\section{II \\ Growth and distributional implications of primarily "growth-oriented" policies}

There is no serious debate about the importance of physical capital formation, human capital accumulation and technological change as sources of growth. The only discussion revolves around their relative importance and how this varies by setting, and around how best each of them may be achieved. In the latter context such policies as fiscal and trade policy are naturally involved. The distributional implications of these three processes are more complicated and may depend very much on the details of the case.

\section{Conservative macroeconomic policy}

It is accepted that runaway inflation is prejudicial to growth. Whether or under what range of circumstances low inflation (say single-digit) produces better growth results than low double-digit levels is much less clear. The current (strong) preference for quite low rates of inflation seems to be based primarily on conservative ideology (whose predictions may of course turn out to be right) and on the perception that high inflation is more problematic in the context of the high level of integration towards which the world is evolving. It does appear that hyperinflation has a negative impact on distribution, although this may be relatively short-lived and is in any case not a major determinant of inequality.

\footnotetext{
${ }^{3}$ The history of ideas about poverty and its relationship to growth, as well as many issues relating to poverty policy, are reviewed in Lipton and Ravallion (1995).
} 
It is also often argued that the "inflation tax" resulting from even intermediate levels of inflation is significantly regressive, in which case lax monetary policy is likely to be regressive as well. But the evidence is fragile and there is little theoretical reason to expect the effects to go one way or the other, unless there is a correlation between the looseness of monetary and fiscal policy and the distribution of net benefits from them (taxes, government expenditures, access to credit). It is fairly widely believed that the low real interest rates which have tended to accompany high rates of inflation tend to produce a more concentrated distribution of credit than would rates closer to market levels (Fry, 1988, p. 163), but here too the evidence is still very sparse. Hypotheses on the distributional implications of loose as opposed to tight fiscal policy are more varied, with nothing approaching consensus (Whitehead, 1996). Overall, while there is no wellgrounded reason to believe that these policies have important direct effects on equity, the credit, tax and public expenditure patterns which go with them may matter a good deal, albeit in ways not yet well understood.

The complexities of the impact of macroeconomic policy on distribution and poverty are further underlined by the recent theories of hysteresis of social conditions over the course of the business cycle; these argue, for example, that poverty, human capital and employment are not affected symmetrically by the downturn and subsequent recovery which together constitute a business cycle, since the gains in the recovery tend to be less than the losses in the downturn. Thus, a business cycle is not a neutral event in the sense that when gross domestic product (GDP) has returned to its pre-recession level the same will be generally true of other variables; cyclical behaviour can have permanent costs in terms of holding those variables below the levels they could have reached had the evolution of GDP been less volatile. Related to these propositions is the idea that when price stability (desirable in itself) is obtained at the expense of output growth stability, the net redistributive effects may be adverse (Ocampo, 2002).

The major direct contribution that having a job makes to people's levels of satisfaction, as revealed in the surveys cited above, implies that any policy package which leads to high unemployment (e.g., tight monetary/fiscal policy aimed at achieving payments balance) is doubly problematic. Only if high current unemployment is necessary to assure low future unemployment is such a policy likely to be justified.

\section{Saving and investment policies}

For really fast growth, savings need not only to be high, but to be used effectively as well. Both the cross-country correlation between saving/investment rates and growth, and the fact that the fast-growing countries of East Asia all underwent dramatic increases in their saving rates as part of the growth acceleration (World Bank, 1993), underline the priority status of this variable. Unfortunately, there remains great ambiguity as to what factors help to raise saving in which sorts of countries. Low demographic burdens appear to have helped in East Asia (Bloom and Williamson, 1998); positive real interest rates and strong financial systems appear to raise financial saving (Mason, 1988), although whether they matter to total saving remains unclear (Masson, Bayoumi and Samiai, 1998, p. 497; Akyüz,1995). Fast growth appears to contribute to high saving rates, so the major challenge may be to achieve that first burst of rapid growth.

If saving potential were in fact limited to the rich (say the capitalist class), then there would be a clear trade-off between fast growth and equitable distribution of income. This is not universally the case, as we know from the experience of countries like Taiwan, but it may be that the trade-off is absent only under somewhat limited conditions. It is no doubt better to achieve high saving from a narrow segment of the population than not to get it at all, especially when the objective is alleviation of poverty defined in absolute terms. Where saving is highly concentrated among entrepreneurs, some of whom are not particularly rich, the situation is more acceptable, since the distribution of consumption expenditures is considerably less unequal than that of income.

\section{Human capital accumulation}

Although it is widely accepted that human capital accumulation is important to growth (Schultz, 1961) and the mechanisms linking the two have been studied from various perspectives, our understanding of the role of human capital in the growth process is only modestly greater than it was several decades ago. Mincerian regressions, long the most widely used method of demonstrating the social payoff to education and training, have been shown to be very sensitive to specification problems, especially omitted variables bias and aggregation bias (Rosenzweig, 1999; Schultz, 1989); credentialism, although its possible quantitative importance has been harder to demonstrate, also 
continues to cast doubts on the simpler Mincerian interpretation of earnings differentials and to suggest that they suffer from upward bias (Dore, 1976). On the other hand, positive externalities related to the process of imitable innovation, skill acquisition from the more educated and the like could be significant also, and would tend to produce a downward bias in the standard estimates. It is reasonable to think that the Mincerian regression estimates do give a very rough feel for social payoffs to education in many circumstances; an estimated $15 \%$ rate of return should probably be interpreted as meaning that the true rate is in the range $5-20 \% .{ }^{4}$ A convergence between the Mincerian regression results and evidence from other methodologies would be needed to narrow the range of uncertainty. ${ }^{5}$ With practical training of various sorts (including periodic over-career upgrading of skills) much under discussion now, and relevant in various ways to poverty alleviation, it is discouraging that earnings function analysis has even more obvious difficulties in sorting out the benefits of these forms of human capital than those of formal education.

The Mincerian estimates have been a source of optimism not only for their generally medium to high estimates of the overall social returns to further human capital accumulation, but also for their indication that such returns are particularly high for primary education. This underpins the belief that raising the human capital of those towards the bottom of the educational and earnings profiles is a useful anti-poverty tool, perhaps even the most important tool of all. But there is still only a limited understanding of what steps will in fact narrow educational gaps (this requires, for example, an understanding of the response pattern from those on the upper side of the educational gaps) and of how the future of education-related earnings gaps may unfold. The empirical evidence linking human capital advances to better growth and distribution outcomes is too flimsy to provide a substitute for detailed understanding of what goes on inside this "black box". It is quite possible, especially given the apparent importance of the skills that are complementary to computer literacy and the information revolution, and of the widely observed increases in earnings gaps by

\footnotetext{
${ }^{4}$ Estimates like that of Behrman and Deolalikar (1993) suggest that the true effects of education on productivity might be as low as $40 \%$ of those implicit in the simple Mincerian regressions.

${ }^{5}$ Pritchett (1996) puts the confusion in this area quite starkly. There has been too much simplistic analysis and too little concern about the manifold methodological problems.
}

level of education over the last decade or so (Robbins, 1995), that the relative payoff to higher as opposed to lower levels of education has risen for the medium term. Keeping well trained people in the country is increasingly difficult to the extent that high-level migration gets easier in a context of globalization; the migration option may be one of the factors behind rising earnings gaps in developing countries (Hamada and Bhagwati, 1975). These considerations could mean that the optimal growth promotion strategy in the area of human capital is no longer as likely to improve distribution or alleviate poverty as it may have been at some point in the past.

The argument for generalized, good quality basic education remains powerful, since the payoffs to literacy and numeracy are evident and since this level is necessary to allow people to advance to the higher ones. The need to worry more about the quality of basic education is made more pressing, however, by the current ambiguities in the evidence of payoff to education in general. Further, and as with most of the other instruments under discussion, the relationship between human capital and poverty is likely to be sensitive to how poverty is defined. This is tautologically the case if one uses a "basic needs" definition in which education figures importantly.

\section{Technological change}

There is no dispute about the importance of saving and investment as a source of growth. In contrast, there is a debate on which new technologies contribute to growth, with theory suggesting that overly modern or capitalintensive ones may not do so, whereas "intermediate" or appropriate technologies are a surer bet. Empirical confirmation of this presumption is limited and for the most part indirect, however, and there is considerable doubt as to whether the shelf of appropriate technologies available is very well stocked.

The distributional impacts of technological advance are also ambiguous. Simple theory suggests strongly that modern technology, in creating few jobs per unit of investment, will tend to worsen the distribution between capital and labour income, and that where such technology is also skill-intensive it will likewise worsen the distribution between more skilled and less skilled workers. Partly because we do not have indicators of the rate or pattern of technological change (in contrast to human capital formation, saving, etc., for which we do have useful measures), it has been difficult to get an empirical feel for the validity of these 
theoretical presumptions. Technological change can be a threat to equitable distribution and hence to poverty alleviation, either because it has a bias towards capital or skilled labour, or because businesses that are in a position to adopt it are already better off (for example, because they are larger) than those not so favourably placed. Certain changes in agriculture can produce a negative distributional impact through both factors, as where tractorization not only lowers costs on large farms in ways which smaller farms cannot replicate, but also displaces labour and pushes more workers on to the smaller farms. ${ }^{6}$ In other sectors, too, the size and existing technologies of the firms which introduce new technologies are both relevant to the final impact of that adoption (James, 1998; Berry, 1998a).

Some aspects of the process of technological change are more exogenous to individual developing countries, and even to the group as a whole, than is the case with the other sources of growth discussed above. It is widely noted that about $97 \%$ of research and development expenditures occur in the industrialized countries of the North (World Bank, 1999). Accordingly, it may be very hard for developing countries, particularly those that are tightly tied into the world economic system, to buffer themselves against some of the negative effects arising from the pattern of ongoing technological change at the world level. Still, a good deal of the evolution of technological practices is affected by the internal context and policies. Though key breakthroughs in agricultural research usually come from outside the country, it is important for their effective adoption, and especially their adoption by smaller farmers, that such international research be complemented by local efforts (Evenson, 1975). In other sectors there are a number of policies that clearly contribute to the rate of technological improvement by smaller firms (Levy, Berry and Nugent, 1999), whose measures are usually more favourable to employment than those adopted by larger counterparts.

\section{Outward orientation and other pro-market policies}

The proponents of freer trade, less government intervention and more market-friendly economic policies generally have argued that this sort of shift will raise the rate of growth not only through Heckscher-

\footnotetext{
${ }^{6}$ The World Bank's somewhat belated recognition of this threat came in the early 1970s. A study of the results of (large) tractorization in Pakistan helped to produce it.
}

Ohlin efficiency effects (Feder, 1983) but also by contributing positively to domestic saving, foreign saving (capital inflows) and the rate of technological change as a result of greater contact with foreign sources, etc. (Rodrik, 1995, pp. 2933-2934). There is no doubt that each of these factors is frequently at work. On the other side of the ledger are the negative effects of instability in the capital inflows and outflows which have come with freer international capital movements, and a possibly negative effect on investment when freer markets lower the certainty about the payoff to certain investments. Also, to the extent that some degree of protection is justified by the presence of learning-bydoing effects as formalized in the "infant industry argument", the inability to protect may hinder countries from helping along nascent industries which could become competitive. Under what circumstances the positive effects of outward orientation will prevail remains to be seen. Given that, with only a few exceptions, the shift to market-friendly policies has not yet brought the developing countries an immediate or large positive impact on growth, the case cannot be considered closed. It may be that those effects will ultimately be significantly positive as anticipated by the proponents, but that a longish gestation period is required for the benefits to manifest themselves fully, or it may be that the optimism was simply ill-founded. The level of analysis which provided the basis for the policy shift was far from exemplary. ${ }^{7}$ Nor does economic theory help much to clarify what trade policies are likely to work best in developing countries; too much depends on the assumptions fed into the theory. When investor risk-aversion is strong and learning by doing is important, it is likely that infant industry protection will be necessary to induce some investments which contribute to growth. If developing countries were highly effective in the design and implementation of policy intervention, free trade would

\footnotetext{
${ }^{7}$ For example, although much use was made of cross-country regressions showing a positive correlation between outward orientation and growth, relatively little attention was paid to the fact that the presence of a positive impact on individual countries does not necessarily or generally imply a positive impact for the Third World as a whole - a classic example of the fallacy of composition. This issue is discussed in the context of primary exports by Maizels (1994), among others, and in that of manufactures by Faini, Clavijo and Senhadji-Semlali (1992) and by UNCTAD (1996). An even graver flaw, because less obvious to the untrained eye, has been the carelessness evinced in the measurement of "outward orientation". Alternative measures, each with some apparent logic, are not well correlated with one another.
} 
probably not be their first-best option; their frequent failure to apply infant industry protection in a way close to that contemplated in the theory makes substantially free trade look like a more attractive "second-best".

There is a strong possibility that outward-oriented policies are the best way to go for small countries but less so for large ones. When Peru adopted import substitution industrialization (ISI) strategies from the 1950s onward, the results appear to have been much less favourable than those in Brazil, which between 1945 and 1980, under strong ISI policies, outgrew almost every other country in the world (Maddison, 1992). Growth achieved by inducing multinational corporations to invest in labour-intensive exports is much more relevant to the smaller countries than to the half-dozen or so in which the bulk of the less developed countries' population lives.

The distributional implications of freer markets, including freer trade and international capital movements, are hotly debated. Positive HeckscherOhlin effects are expected by most proponents on the basis of the ideas that, firstly, developing countries typically have a comparative advantage in labourintensive goods and services so that freer trade should increase the relative demand for labour and hence improve the distribution of income and, secondly, that freer trade in many countries implies a stronger demand for agricultural products whose exports are indirectly discouraged by ISI policies mainly designed to protect manufacturing. Prominent among the various counterarguments is the empirical fact that the recent wave of globalization and liberalization of trade and capital movements has coincided with increasing inequality in many developing countries (Berry and Stewart, 1997) as well as in the developed ones; this fact throws doubt on whether Heckscher-Ohlin effects are working as strongly as predicted. ${ }^{8}$ For some regions (like Latin America) the explanation for their not doing so may be that these countries' comparative advantage at a world level does not in fact lie in unskilled labour-intensive goods and services, but rather in goods intensive in natural resources or relatively skilled labour, or both. More generally, the fact that firms which engage heavily in international trade tend to be larger (industry held constant) than those which do not, and also tend to use more capital-intensive and modern technologies, suggests that distribution will tend to worsen as the share of output which is traded internationally rises.

Putting together the still doubtful growth effects of freer trade with the negative distributional trends which have frequently coincided with the policy shift makes it evident that any presumption that freer markets will bring significant poverty alleviation should be put on hold. Perhaps the most likely outcome is a small positive impact on growth together with a negative impact on distribution of medium scope, leaving a small net effect, possibly positive and possibly negative, on the rate of absolute poverty alleviation. But the range of possible effects is wide, given our lack of understanding of the mechanisms involved and the rather confusing empirical record thus far. In a society which places substantial weight on relative income, the impact of this policy shift on poverty could be strongly negative if the distributional effect is significantly negative.

\footnotetext{
${ }^{8}$ Various empirical studies have reached more positive judgements. Thus, Londoño and Székely (1998) concluded on the basis of crosscountry regressions for Latin America that trade reform had produced a positive impact on distribution, while labour reform had had the opposite effect. Stallings and Peres (2000) found that both trade reform and tax reform had negative impacts on household distribution. Morley (2000) also found the impact of trade reforms to be negative. Though they estimated a positive effect from the reforms, Londoño and Székely concluded that the reforms alone would not bring marked improvements in inequality or poverty unless they had the effect of diminishing educational inequality and widening access to other productive assets.
} 


\section{III}

\section{Distribution and growth implications of primarily “distribution-oriented" policies}

As with the main components of the more growthoriented policies, each of the distribution-oriented policies considered below may have significant growth impacts besides the effects on distribution for which they are more often implemented.

\section{Asset redistribution policies}

The most obvious way to improve income distribution is through a redistribution of productive assets. In the case of human capital, this can only be done gradually over the course of time since expropriation and immediate redistribution is not feasible. With physical assets such redistribution is possible, but seriously feasible only with land, i.e., via land reforms. That these can have a substantial and lasting effect on income distribution under favourable circumstances is clear. Taiwan province of China is the most commonly cited case; it appears that inequality fell markedly at the time of the reform, undertaken when the country was still mainly agricultural (Kuo, 1983, pp. 94-97). The subsequent trajectory has been an exceptionally positive one in terms both of growth and of distribution. It appears that the initial equality contributed to its own perpetuation by helping to produce a very equal distribution of educational opportunities, dynamic growth of small enterprise, first in rural and then in urban areas, and a stronger political voice for the representatives of small enterprise. But few countries have had significant agrarian reforms, so the number of experiences is too small to permit a judgement on the range of circumstances under which the effects would be as positive as they appear to have been in Taiwan or Korea. It is also clear that only very unusual political conditions open the door for a major land reform to take place. It therefore appears destined not to be an important component of many poverty alleviation strategies, even though it may in principle be the most promising of all in many of the less developed countries.

Some attention has recently been given to the potential of market-based land reforms, in which subsidies to help small farmers buy land replace expropriation as the means of land transfer. The economic logic of these reforms is promising (Deininger, 1999), although it seems unlikely that such approaches will in practice have more than a marginal impact on the agrarian structure if applied without traditional confiscatory land reform. When complemented by such traditional reform, they may have greater value, partly through the "threat effect" which can make landlords more flexible in the face of expropriation. Removal of legal constraints on land subdivision is a minimal enabling device (Lipton, 1993, p. 651). Removal of subsidies favouring large farmers or their crops can be a valuable supportive device for credit or land laws to help the poor, and can be nudged along by the fiscal stringency faced by so many countries. Lower subsidies helped discourage the rich from subverting reforms in north-east Brazil, though other positive steps were also taken there.

Forest dwellers in many countries have faced expulsion from their natural-resource bases as other actors, sometimes private lumber companies and sometimes the State, put pressure on them. In this sector, as in agriculture, good distribution and efficient production often go together, as demonstrated by the success of community-managed forests (which produce a range of timber and non-timber products) in a number of the states of India (Kant, 1996) and elsewhere (Brightman, 1987). In 1988 the Government of India finally gave up on its former policy of excluding such dwellers from forest management, in recognition of the failure of that policy on both output and distribution grounds (Kant and Berry, 1999).

\section{Policy in support of small farms and micro, small and medium-sized enterprise}

Much more feasible politically than asset redistribution policies (mainly land reform) are forms of support for the small firms, in agriculture and outside, which are the base of employment for the majority of the labour force in most developing countries. Such support, to the degree that it raises output and productivity in these firms, directly increases the incomes of many poorer 
people. Its other advantage comes from the fact that smaller firms, whatever the industry, tend to be more labour-intensive than larger ones, so their presence raises the total demand for labour relative to what it would have been if their place had been taken by larger firms. Although small enterprises often generate low incomes, their productivity level (output per unit of scarce inputs) is often high, albeit varied. Medium-sized firms frequently achieve the highest total factor productivity of all the size categories, and thereby contribute to high incomes and to growth (Ho, 1980). Small and medium-sized enterprises (SMEs) contribute to a more equitable distribution since their factor proportions tend to be close to those of the economy as a whole.

Raising the productivity of small farms and of microenterprise has an immediate effect on poverty. In the former case the sources of success are clear - the sort of improvements in crop varieties which defined the green revolution. In the case of non-agricultural microenterprise, much effort has gone into improving credit access on the assumption that this will lead to higher productivity and hence incomes. A major challenge here is to assure the sustainability of the credit institutions; most experiments thus far have failed to pass this test (Santor, 1999). On the equally important question of whether their social benefit-cost ratio is adequate, the evidence is harder to come by and thus far uncertain. ${ }^{9}$ If the available support programmes turn out not to have strong potential to raise the collective productivity of microenterprise, then a dilemma will arise as to whether such support is a more or less effective way of alleviating some poverty than is targeted poverty alleviation involving transfers of one sort or another to the poor.

\footnotetext{
${ }^{9}$ While it is clear in many cases that the credit recipients have done better than non-recipients, this leaves open the question of whether the gains of the former have been at the expense of losses among the latter, a not implausible scenario in cases like smallscale retailing where the structure is one of monopolistic competition and the total market size may be quite constrained. A recent, impressive study of the main microfinance institutions in Bangladesh is that of Morduch (1998).
}

If it is not feasible to achieve considerable productivity increases in very small enterprises, the next most direct way to alleviate poverty is to encourage a rapid expansion of small to medium-sized enterprise, which will eventually tighten up the labour market and create jobs for those currently lodged in the less productive microenterprise sector (Berry, 1998b). Depending on the country, this impact on poverty may come very quickly or with some lag.

\section{Direct poverty-redressal policies}

All societies have ways of alleviating the poverty of those with inadequate entitlements on the basis of their own efforts or opportunities. In developing countries, most such mechanisms involve the family (including the extended family) or the community. Developing countries have been evolving targeting techniques over the last decade or so; the statistical record, while still ambiguous, holds out a reasonable hope (Grosh, 1995) that, with further experimentation and refinement, they may play an increasing role in poverty alleviation over the next few decades, in some countries at least. ${ }^{10}$

A number of higher-income developing countries (several in Latin America, for example) are moving towards such developed-country staples as unemployment insurance. These too will inevitably go through a period of experimentation before it becomes clear what role they can and should play. The same goes for the various "safety net" public employment programmes which a number of governments have implemented over the last few decades, from the Indian state of Maharashtra to Chile under Pinochet. These pay a low enough wage to ensure that only the needy take up the employment option offered, and they attempt to generate social benefits in the form of infrastructure (road maintenance, school building, other).

\footnotetext{
${ }^{10}$ Ocampo (2001, p. 25) notes that in two of the three countries of Latin America where rural poverty reduction was most marked in the 1990s, namely Brazil and Chile (the other was Panama), the reduction was closely tied to an allocation of transfers and State subsidies targeted on the poorer sectors.
} 
IV

\section{Policy priorities vary with the definition of poverty}

Past errors in the interpretation of how development occurs have been at least matched by oversimplification in the matter of defining poverty. Social scientists other than economists (especially sociologists and psychologists) have long emphasized that people's feelings of deprivation are very much related to relative income and purchasing power and the feelings of inferiority which arise when these are low, especially in competitive societies where people are judged by their relative success. The concentration of economists on income-related measures of welfare may have been no more than a naïve prejudice, on balance ill-supported by other more direct evidence. Specifically, when people in the industrial countries (where such surveys have been carried out with some frequency) are directly consulted about their happiness and its correlates, absolute income seems to play a much smaller role than standard economic theory would suggest. It is moderately significant when the comparison is between people at different levels of the income hierarchy at a point of time, but less so -some authors say virtually insignificant- as a factor in how average societal welfare changes over time, even when average incomes have risen considerably (Easterlin, 1974; Scitovsky, 1976; Oswald, 1997). Most such studies reveal that the strongest influence among economic variables comes from employment; people with jobs are much happier than those without them. ${ }^{11}$ Low inflation also makes people happier. The educated are happier than the uneducated, the self-employed than employees and the retired than the economically active. The ultimate meaning of all this evidence remains to be seen; in particular, the small apparent role of income cries out for analysis. ${ }^{12}$

\footnotetext{
${ }^{11}$ This is presumably due in part to unhappy people having trouble finding jobs, but longitudinal studies by psychologists have demonstrated that this is not the only cause (Oswald, 1997, p. 1822). ${ }^{12}$ Though rising average income does not appear to lead to anything like commensurate increases in average happiness, it is true that there is a significant cross-section relationship between happiness and income. In the European data for 1975-86, 18.8\% of the bottom quintile report being "very happy" compared with $28.4 \%$ for the top one, while $26.7 \%$ report being "not too happy" compared with $13.1 \%$ for the top quintile (Di Tella, MacCulloch and Oswald, 1996). Part of this correlation would be due to the higher
}

One might plausibly guess that income would be a more significant determinant of self-reported happiness in lower-income (developing) countries, and the available data do show this. Frank (1997, p. 1834) notes that "most careful studies find a clear time-series relationship between subjective well-being and absolute income at low levels of absolute income". Where most people lack minimally adequate shelter and nutrition, additional income yields significant and lasting improvements in subjective well-being (Diener and Diener, 1995). Reported satisfaction levels are significantly lower in extremely poor countries than in rich ones, and within countries the positive link between income and satisfaction is significant primarily at the lowest levels of relative income. "For individuals in the middle and upper portions of the income distribution, variations in income explain less than $2 \%$ of variation in reported satisfaction levels" (Frank, 1997, pp. 18341835, citing Diener and Diener, 1995). Having concluded that average satisfaction levels within a country are not significantly correlated with income over time, Frank puts great emphasis on relative status as a source of respect and a determinant of well-being.

The surprising (to many economists at least) findings on the relative unimportance of income as a determinant of societal welfare may be only one of several reasons for reconsidering the conceptual basis for poverty policy. The role of a sense of belonging to a community in human welfare is obvious at one level, but it remains to be factored into discussions of economic policy. The same may be said of "social capital" (the ability to work effectively with others). Participatory poverty assessments uncover some of the correlates of welfare and deprivation as experienced by the respondents. In his study in the Republic of Guinea, Shaffer (1998) found that, although consumption data revealed no relative deprivation of women vis-à-vis men, two other dimensions which disproportionately affect women surfaced clearly: excessive workloads and lack of decision-making authority/respect.

unemployment rates of the lower-income groups. Over time the happiness of the unemployed shows much more fluctuation than that of the employed, for reasons as yet unexplained. 
The combination of evidence to the effect that more income does make individuals better off than their counterparts with less income, but that when everyone's income rises over time there is no comparable effect on average reported happiness, is consistent with the general notion that people's welfare depends on relative status, which in modern societies is affected by relative income and consuming power. Given such attitudes, deprivation -the reason one is interested in poverty as a problemcan be alleviated mainly, or even exclusively, by reducing the degree of income inequality. But, as many authors have emphasized, a more basic implication of such a situation is that society is dysfunctional in the sense that, as long as it defines satisfaction in relative terms, there is no way to make everyone better off. The gain of people on low incomes who are now closer in status to those above them is a loss to the latter, who can no longer enjoy the feelings of superiority which gave them satisfaction before. A society whose attitudes are less individualistic and competitive and more positively community- or society-oriented has the chance to benefit much more from economic advance. In short, the empirical evidence from the industrial countries suggests that attitudinal change may be more important than economic growth, and that without the former the latter may remain largely irrelevant. Although this is less true of the developing countries, to the extent that they replicate the attitudinal patterns of the rich countries it will become their problem too. A key objective of any society should be to reduce the "zero sum" component of what gives people satisfaction.

Given current attitudes, what does the partial and in some ways puzzling evidence on the determinants of human welfare add up to, in terms of its practical implications for economic policy? Most striking is the ambiguous role of income. Taken literally, the results would seem to suggest that economic growth ought to be severely downgraded in our thinking about poverty and welfare and that socio-economic policy should focus much more than it now does on employment (for those that want it), on employment conditions (including the avoidance of excessive work), on income distribution, on freedom from economic insecurity, on the importance of personal respect, and on sense of community. Whatever the ultimate meaning of the low weight attached to income, a plausible case can be made that most of the other identified correlates of self-declared happiness are associated with one another in a mutually supportive way. To begin with, a (or the) main direct source of high levels of income inequality is an inadequate demand for the labour of those with the least skills, and this also tends to produce unemployment of the more chronic and socially costly type, together with economic insecurity and the anxiety which accompanies it. Income inequality is also associated with an unequal distribution of physical and human capital. These interconnected inequalities are a direct cause of lack of respect for those at the bottom of the pyramids of income, wealth, education, skills, etc. Diminishing the inequalities naturally reduces the number of people subjected to lack of respect from others, even if those others retain an income/wealth/education-related definition of status and respect; although in fact, when these variables do not constitute such a gulf among people, the societal definition of the sources of respect is likely to change in a positive way. When differences among people are smaller, the sense of community is also more developed and positive in its impacts.

As noted above, there has been no general positive trend in income or expenditure distribution over the last half century, and a disproportionate share of countries have recently suffered the opposite pattern. It follows that a poverty indicator which gives enough weight to relative income will show little if any progress over time, especially during the last couple of decades. Thus, the widely differing implications of the alternative poverty indicators that have been put forward suggest an urgent need to consider more seriously which of these are most meaningful and perhaps to identify some professionally defensible combination of them that would give due weight to each of the determinants of deprivation and satisfaction as experienced by individuals. Most of the indicators used by economists are naïve in their implicit assumptions about the sources of individual feelings of deprivation, but thus far little attempt has been made to incorporate anything subjective into the indicators compiled by international agencies and by most economic researchers.

One of the more notable complexities still to be effectively dealt with is that of intra-family inequalities and the way they may have been changing over time. If rising incomes, urbanization and other processes of development have typically brought with them advances in intra-family equality between the sexes, one would conclude that, correctly measured, the distribution of expenditure among persons has evolved more positively than the standard estimates, which assume away intrafamily inequality. How the distribution of subjective welfare has evolved is less clear; if women's expectations have evolved more rapidly than their relative position, for example, subjective welfare distribution might move in the opposite direction from that of expenditures. 
V

\section{What are the best bets? ${ }^{13}$}

Which policy instruments are most effective in alleviating poverty thus depends very much on how poverty is defined. The optimal package is easiest to define when absolute poverty, as measured by income or expenditure per person, is the operative concept. In that case it is clear that growth is central, growth with equity is desirable, and policies whose main objective is redistribution are unlikely to play a large role. The most promising instruments are promotion of a high saving rate, preferably with widespread involvement of the population; investment in human capital, especially for those population groups who lag in that respect; technological change, with a serious effort to keep the innovations within the realm of "appropriate technology"; and policy support for smaller production units. Population policy and asset redistribution may be among these key elements in some countries, institutional reform and monetary/fiscal policy in others. Whether generally market-friendly policies will play a positive or negative role remains to be seen.

As the weight assigned to relative poverty (also defined by income or expenditures per person) and to employment conditions, respect, etc., increases and that assigned to absolute poverty decreases, the relative promise of the various policies is altered, perhaps dramatically. When relative poverty is the dominant concern, support for smaller productive units and attempts to raise the human capital of the poor are probably the best policy options available in most countries; asset redistribution may be the best in some cases where feasible, and significant in others; population policy can be important, especially when complemented by strong gender policies in countries where inter-gender inequality is significant. Saving and technology policies are question marks in this situation, since there is no general presumption that they can improve distribution even if executed fairly carefully with that objective in mind. Market-friendly policies are an unlikely component of the package. ${ }^{14}$ These

\footnotetext{
${ }^{13}$ Among many reviews of poverty reduction strategies are Shaffer's report to the United Nations (United Nations, 1998), Chatterjee's paper for the Asian Development Bank (Chatterjee, 1995) and Lipton and Ravallion (1995).

${ }^{14}$ This is a very broad-brush discussion. Within the category of market-friendly reforms there are some which are quite likely to
}

policies may be deleterious in another way; to the extent that they focus on market competition as the route to wealth for individuals, firms, regions, etc., they may heighten people's awareness of their relative position and thereby make the perceived deprivation of those performing less well in the market that much more acute.

Since almost all students of poverty would grant that, if income and expenditures are the relevant indicators, both absolute and relative positions affect welfare, we are left with the conclusion that the optimal package will be somewhere between the two just identified, closer to the first if absolute poverty is more important and closer to the second if relative poverty is more important.

The aspect of relative position which can most easily be taken into account in the measurement of change is relative income. But, as noted, an individual's welfare involves also the way he or she is treated by others and the related sense of social inferiority, the lack of access to psychological support, etc. Discriminatory treatment towards women, the aged, children or subordinated ethnic groups all figure importantly in the loss of welfare. Accordingly, measures of societal welfare should take these forms of inequality into account directly. While some societies have made progress in dealing with ethnic and gender inequality, the problems associated with age may have on balance become more severe as more people live to advanced ages and as family responsibility for that group diminishes.

The task of policy prescription is altered again and perhaps made more complex when poverty is defined in other, more subjective ways which allow for the benefits of feelings of community and feelings of security (not taken account of in the absolute or relative income figures, although well enough reflected in the market behaviour of individuals in the form of insurance purchases, risk aversion in investment behaviour, etc.). Without some concrete feel for societal preferences as to what the good life is (and recognizing that such perceptions are themselves to some extent dependent

worsen income distribution and others which are quite likely to improve it. 
on past and current experience), it is impossible to take strong positions on what good policy is. It is clear, though, that it might look rather different from what such policy would be when the indicators were objectively measurable income or expenditure.

Desire for security is not necessarily inconsistent with a need for adventure as well; societies need to search for good ways to reconcile these goals. If access to opportunities is more important to satisfaction than ex post success in economic terms, this too alters the way in which both overall economic performance and the degree of inequality in a society should be measured. Unfortunately, the concrete policy implications of these plausible components of social welfare are at this time fuzzy, for lack of careful assessment of what they might imply in practical terms.

\section{Bibliography}

Akyüz, Y. (1995): Financial liberalization in developing countries: Keynes, Kalecki and the rentier, in G. Helleiner, S. Abrahamian and others (comps.), Poverty, prosperity and the world economy: Essays in memory of Sidney Dell, Portland, Book News.

Behrman, J.R. and A.B. Deolalikar (1993): Unobserved household and community heterogeneity and the labor market impact of schooling: a case study for Indonesia, Economic Development and Cultural Change, vol. 41, No. 3, Chicago, April.

Berry, A. (1998a): The impact of globalization and information technology on Latin America, in A.S. Bhalla (comp.), Globalization, growth and marginalization, London, The Macmillan Press.

(1998b): Las tareas de la pequeña y mediana empresa en América Latina, CEPAL Review, special issue (LC/G.2037-P), Santiago, Chile, October.

Berry, A. and F. Stewart (1997): Market liberalization and income distribution: the experience of the 1980s, in R. Culpeper, A. Berry and F. Stewart (comps.), Global development half a century after Bretton-Woods, London, The Macmillan Press.

Berry, A. and J. Serieux (2002): Riding the elephants: World economic growth and income inequality at the end of the 20th century (1980-2000), Toronto, Centre for International Studies, University of Toronto.

Berry, A., F. Bourguignon and C. Morrisson (1983): Changes in the world distribution of income between 1950 and 1977, Economic Journal, June.

Bloom, D.E. and J.G. Williamson (1998): Demographic transition and economic miracles in East Asia, World Bank Economic Review, vol. 12, No. 3, September.

Brightman, R.A. (1987): Conservation or resource depletion: the case of the boreal forest Algonquians, in B.J. McKay and J.M. Acheson (comps.), The question of the commons, Tucson, University of Arizona Press.

Chatterjee, S. (1995): Growth, structural change and optimal poverty interventions, Occasional Papers, No. 13, Manila, Asian Development Bank.

Deininger, K. (1999): Making negotiated land reform work: Initial experience from Colombia, Brazil and South Africa, World Development, vol. 27, No. 4, Amsterdam and New York.

Di Tella R., R. MacCulloch and A.J. Oswald (1996): The macroeconomics of happiness, Oxford and Warwick, unpublished.

Diener, E. and C. Diener (1995): The wealth of nations revisited: income and the quality of life, Social Indicators Research, vol. 36 .
Dore, R. (1976): The diploma disease: Education, qualification and development, Berkeley, University of California Press.

Easterlin, R. (1974): Does economic growth improve the human lot? Some empirical evidence, in P.A. David and M.W. Reder (comps.), Nations and households in economic growth: Essays in honour of Moses Abramovitz, New York and London, Academic Press.

Evenson, R. (1975): Technology generation in agriculture, Agriculture in development theory, L.G. Reynolds (comp.), New Haven, Yale University Press.

Faini, R., F. Clavijo and A. Senhadji-Semlali (1992): The fallacy of composition argument: is it relevant for LDCs' manufactures exports?, European Economic Review, vol. 36.

Feder, G. (1983): On exports and economic growth, Journal of Development Economics, vol. 12.

Frank, R. (1997): The frame of reference as a public good, Economic Journal, vol. 107, November.

Fry, M.J. (1988): Money, interest, and banking in economic development, Baltimore and London, Johns Hopkins University Press.

Grosh, M. (1995): Five criteria for choosing among poverty projects, in N. Lustig (comp.), Coping with austerity: Poverty and inequality in Latin America, Washington, D.C., The Brookings Institution.

Hamada, K. and J. Bhagwati (1975): Domestic distortions, imperfect information and the brain drain, Journal of Development Economics, vol. 2, No. 3, September.

Hirsch, F. (1976): The social limits of growth, Cambridge, Massachusetts, Harvard University Press.

Ho, S.P.S. (1980): Small-scale enterprise in Korea and Taiwan, World Bank Staff Working Paper, No. 384, Washington D.C., World Bank.

James, J. (1998): Information technology, globalization and marginalization, in A.S. Bhalla (comp.), Globalization, growth and marginalization, London, Macmillan Press.

Kant, S. (1996): The economic welfare of local communities and optimal resource regimes for sustainable forest management, $\mathrm{PhD}$ thesis, Toronto, University of Toronto.

Kant, S. and A. Berry (1999): Path dependence, multiple equilibria, and adaptive efficiency in forest regimes in India, Toronto, unpublished.

Kuo, S.W.Y. (1983): The Taiwan economy in transition, Boulder, Colorado, Westview Press.

Kuznets, S. (1955): Economic growth and income inequality, American Economic Review, vol. 45, No. 1.

Levy, B., A. Berry and J.B. Nugent (1999): Fulfilling the export potential of small and medium firms, Norwell, Massachusetts, Kluwer Academic Publishers. 
Lipton, M. (1993): Land reform as unfinished business: the evidence against stopping, World Development, vol. 21, No. 4, April.

Lipton, M. and M. Ravallion (1995): Poverty and policy, in J. Behrman and T.N. Srinivasan (comps.), Handbook of Development Economics, vol. 3B, Amsterdam, Elsevier Science B.V.

Londoño, J.L. and M. Székely (1998): Sorpresas distributivas después de una década de reformas, Revista de Economía Política, special volume.

Maddison, A. (1992): The political economy of poverty, equity, and growth: Brazil and Mexico, Oxford, World Bank, Oxford University Press.

Maizels, A. (1994): The continuing commodity crisis of developing countries, World Development, vol. 22, No. 11.

Mason, A. (1988): Saving, economic growth, and demographic change, Population and Development Review, vol. 14, No. 1.

Masson, P.R., T. Bayoumi and H. Samiai (1998): International evidence on the determinants of private savings, World Bank Economic Review, vol. 12, No. 3, September.

Morduch, J. (1998): Does microfinance really help the poor? New evidence from flagship programs in Bangladesh, Research Program in Development Studies, Princeton, Princeton University, draft.

Morley, S. (2000): Distribution and growth in Latin America in an era of structural reform, document prepared for the Conference on Poverty and Income Inequality in Developing Countries, Paris, 30 November-1 December.

Ocampo, J.A. (2001): Agricultura y desarrollo rural en América Latina, in M.B. David (comp.), Desarrollo rural en América Latina y el Caribe ¿la construcción de un nuevo modelo?, Bogota, ECLAC/Alfaomega.

(2002): Lights and shadows in Latin American structural reforms, document presented at the Conference in honour of Professor Albert Berry, Toronto, University of Toronto, 19 and 20 April.

Oswald, A. (1997): Happiness and economic performance, Economic Journal, vol. 107, London.

Pritchett, L. (1996): Where has all the education gone?, Policy Research Working Paper, No. 1581, Washington, D.C., World Bank.

Ranis, G. (1978): Equity with growth in Taiwan: How 'special' is the 'special' case?, World Development, vol. 6, No. 3, March.

Robbins, D. (1995): Trade and industrial policy reform, in J. Behrman and T.N. Srinivasan (comps.), Handbook of Development Economics, vol. B, Amsterdam.

(1996): Evidence on trade and wages in the developing world, OECD Development Centre Technical Paper, No. 119, Paris, December.

Rodrik, D. (1995): Why is there multilateral lending?, NBER Working Papers, No. 5160, Cambridge, Massachusetts, National Bureau of Economic Research.

Rosenzweig, M. (1999): Schooling, economic growth, and aggregate data, in G. Saxonhouse and T.N. Srinivasan (comps.), Development, duality, and the international economic regime: Essays in honor of Gustav Ranis, Ann Arbor, University of Michigan Press.

Santor, E. (1999): Microfinance: A review of theory, practice and impact, document prepared for the Department of Economics of the University of Toronto, Toronto.

Schultz, P. (1989): Education investments and returns, in H. Chenery and T.N. Srinivasan (comps.), Handbook of Development Economics, vol. 2, Amsterdam, Holland.

Schultz, T.W. (1961): Investment in human capital, American Economic Review, vol. 51, No. 1, March.

Scitovsky, T. (1976): The joyless economy, Oxford, Oxford University Press.

Serieux, J. and A. Berry (1999): Convergence, divergence or novergence? Recent trends in world income distribution, 19801995, unpublished.

Shaffer, P. (1998): Gender, poverty and deprivation: Evidence from the Republic of Guinea, World Development, vol. 26, No. 12.

Stallings, B. and W. Peres (2000): Crecimiento, empleo y equidad: El impacto de las reformas económicas en América Latina y el Caribe, Santiago, Chile, Fondo de Cultura Económica/ Economic Commission for Latin America and the Caribbean (ECLAC).

UNCTAD (United Nations Conference on Trade and Development) (1996): World economic and social survey 1996, New York.

United Nations (1998): Poverty reduction strategies: A review, New York.

Whitehead, C. (1996): Chronic fiscal stress and the reproduction of poverty and inequality in Latin America, in V. BulmerThomas (ed.), The new economic model in Latin America and its impact on income distribution and poverty, Basingstoke, Macmillan/New York, St. Martin's Press, in association with the Institute of Latin American Studies, London.

World Bank (1993): The East Asian miracle: Economic growth and public policy, New York, Oxford University Press. D.C.

(1997): World development review 1997, Washington,

(1999): World development review 1998-99: Knowledge for development, Washington, D.C. 